\title{
Remembering: The role of extraneous reinforcement
}

\author{
GLENN S. BROWN and K. GEOFFREY WHITE \\ University of Otago, Dunedin, New Zealand
}

\begin{abstract}
In two experiments, pigeons' responding on an extraneous task was explicitly reinforced during delayed matching-to-sample trials. In Experiment 1, red or green sample stimuli were followed by retention intervals of $0.2,1,4$, or $12 \mathrm{sec}$, during which pecks to a white center key were reinforced with 2.5-sec access to wheat according to extinction, variable-interval 30-sec, and variable-interval 15 -sec schedules in different conditions. A proportion of $.2, .5, .7$, or .9 of subsequent red or green choice responses that matched the sample were reinforced with 3-sec access to wheat. The result was that increasing center key reinforcement, or reducing reinforcer probability, lowered overall accuracy. Initial discriminability fell, but with no change in the rate of forgetting. In Experiment 2, initial discriminability was affected by extraneous reinforcers that were contingent on center key pecking, but not by noncontingent reinforcers. A plausible conclusion is that initial discriminability decreases when reinforcers strengthen competing behaviors.
\end{abstract}

Traditionally, the role of reinforcement in remembering has received less attention than its role in the acquisition and maintenance of other behaviors. Remembering is typically studied using the delayed matching-to-sample (DMTS) procedure (Blough, 1959). In this discrete-trial paradigm, subjects choose between behavioral alternatives $B_{1}$ and $B_{2}$ following the presentation of a sample stimulus, $S_{1}$ or $S_{2}$, seconds earlier. Typically, $B_{1}$ is "correct" and reinforced only when $S_{1}$ was presented. Likewise, $B_{2}$ is reinforced only when $S_{2}$ was presented. Logically, accurate performance (often called matching-i.e., $B_{1} \mid S_{1}$ and $B_{2} \mid S_{2}$ ) relies on the ability to discriminate $S_{1}$ from $S_{2}$ and $B_{1}$ from $B_{2}$. Often overlooked, however, is the fact that reinforcement is central. Without it, remembering would not be observed. It is well established that the effects of reinforcers on a behavior are modulated by the reinforcers for other, extraneous behaviors (Herrnstein, 1970; Williams, 1988). That is, the effects of reinforcement depend on the reinforcement context. In the present experiments, we ask whether this relativity also applies to remembering. Specifically, does the rate of reinforcement for an extraneous behavior influence the accuracy of performance in DMTS?

The present research was supported by a University of Otago Postgraduate Scholarship to G.S.B. A portion of the research was presented to the Association for Behavior Analysis, New Orleans, May 2001, with the support of an NZVCC Claude McCarthy Fellowship to G.S.B. It was also presented to the New Zealand Behaviour Analysis Group, Hamilton, August 2000, with assistance from the University of Otago Memory Research Theme. Correspondence and requests for electronic copies of analytical programs and spreadsheets may be requested from K. G. White, Department of Psychology, University of Otago, P.O. Box 56, Dunedin 9001, New Zealand (e-mail: kgwhite@otago.ac.nz).

\section{Quantification of Delayed Matching Performance}

Accuracy in DMTS is often measured using proportion correct (White, Ruske, \& Colombo, 1996). Its advantage is that it is never infinite, but it is subject to ceiling effects (Brown \& White, in press; Nevin \& Grosch, 1990; White, 2001). It is thus difficult to distinguish different levels of highly accurate performance and to interpret interactions between conditions (Loftus, 1978; Wixted, 1990). Furthermore, if choices are biased toward a particular alternative, proportion correct drops even if subjects are no less able to discriminate the sample stimuli. Accordingly, Davison and Tustin (1978) suggested the discriminability measure $\log d$. Its formula is

$$
\log d=\frac{1}{2} \cdot \log \left(\frac{B_{1} \mid S_{1}}{B_{2} \mid S_{1}} \cdot \frac{B_{2} \mid S_{2}}{B_{1} \mid S_{2}}\right) .
$$

It avoids ceiling effects by taking the ratio of correct to error responses (Nevin \& Grosch, 1990) and ignores bias by taking the geometric mean of those ratios for $S_{1}$ and $S_{2}$. Log $d$ is almost linearly related to $d^{\prime}$ (Macmillan \& Creelman, 1991) from signal detection theory (Green \& Swets, 1966) and is directly proportional to $\ln \alpha$ from choice theory (Luce, 1963).

The delay between the sample and the choice (the retention interval) is often varied in DMTS experiments (White, 1985). When $\log d$ is measured at each retention interval, the result is a forgetting function that typically falls as the retention interval lengthens (White, 1985, 1991, 2001). It usually does so in a monotonic curvilinear fashion that is well approximated by several mathematical functions (Rubin \& Wenzel, 1996; Wixted \& Ebbesen, 1991). White (2001) preferred one of the best-fitting functions, 
the negative exponential, on the theoretical grounds that its rate of decrement is independent of the time elapsed since stimulus presentation. Its equation is

$$
\log d_{t}=\log d_{0} \cdot e^{-b t},
$$

where the $y$-intercept (initial discriminability) is represented by the free parameter $\log d_{0}$ and the slope, or rate of forgetting over time $t$, is represented by $b$.

Initial discriminability is influenced by factors that are independent of the retention interval (White, 1985, 2001). Such factors include the similarity of sample stimuli (White, 1985) and the response requirement (Roberts, 1972) or duration (Nelson \& Wasserman, 1978) of the sample. The rate of forgetting, on the other hand, is controlled by factors that depend on the length of the retention interval (Harper \& White, 1997; White, 2001). For example, when food (Jans \& Catania, 1980) or a houselight (Harper \& White, 1997; Roberts \& Grant, 1978; White, 1985) are presented for the duration of the retention interval, the rate of forgetting increases. When they are presented for a constant amount of time - that is, a duration that is independent of the retention interval - rate of forgetting does not change, and initial discriminability decreases (Harper \& White, 1997). Because rate of forgetting is time dependent and initial discriminability is not, changes in one parameter may be independent of changes in the other (White, 1985, 1991, 2001).

\section{Forgetting Functions and Reinforcement}

Reinforcers are also crucial determinants of the forgetting function. When reinforcers for correct matching in DMTS are delayed, performance becomes less accurate (McCarthy \& Davison, 1986, 1991; Sargisson \& White, 2003; Weavers, Foster, \& Temple, 1998; Wilkie \& Spetch, 1978). This is principally manifest as a reduction in initial discriminability, consistent with a time-independent effect of delayed reinforcement. Sargisson and White showed that the rate of forgetting also increases, consistent with a greater disruptive effect of delayed reinforcement at low levels of discriminability. A similar effect on the forgetting function is generated by the differential outcomes effect. When different qualities or durations of food are provided for correct $B_{1}$ and $B_{2}$ responses, initial discriminability is higher, and forgetting is less rapid (Brodigan \& Peterson, 1976; Jones \& White, 1994; Jones, White, \& Alsop, 1995). This result is consistent with a general improvement in performance (time independent), coupled with a modification of disruptive behaviors that occur during the retention interval (time dependent; Jones \& White, 1994; Trapold, 1970).

A related effect is the signaled magnitude effect. Here, reinforcers are the same for correct $B_{1}$ and $B_{2}$ responses. Their overall short versus long duration, however, is signaled by external stimuli. The result is that initial discriminability is higher when longer reinforcers are signaled, with no change in the rate of forgetting (Brown \& White, 2005; Jones et al., 1995; McCarthy \& Voss, 1995; Nevin \& Grosch, 1990). A similar signaled probability effect was reported by Brown and White. An effect of reinforcer probability can also be demonstrated between conditions. White and Wixted (1999) manipulated the overall probability of reinforcement for correct matching between conditions. They found a delay-independent increase in accuracy (i.e., a change in initial discriminability, but not in rate of forgetting) when reinforcement for correct matching was overall richer, in keeping with the effect of reinforcement probability on initial discriminability in the within-session procedure reported by Brown and White.

\section{A Role for Extraneous Reinforcement?}

Clearly, reinforcement affects DMTS performance. Nevin, Milo, Odum, and Shahan (2003) suggested that the effect of reinforcers on DMTS accuracy may be similar to their effects on response rate in simple operant tasks. If so, one variable that might affect performance in DMTS is extraneous reinforcement, $R_{\mathrm{o}}$. Its effects on behavior in simple operant tasks are well established (e.g., Herrnstein, 1970). In single-interval schedules, Herrnstein (1970) suggested that relative to the rate of reinforcement for keypecking, increasing $R_{\mathrm{o}}$ reduced the rate of keypecking, a generalization that has strong empirical support (de Villiers \& Herrnstein, 1976). The effect of extraneous reinforcement has been demonstrated experimentally. For example, White, McLean, and Aldiss (1986) programmed a constant rate of reinforcement for left-leverpressing by rats and varied the concurrently available variable-interval (VI) reinforcement rate for right-leverpresses across a series of conditions. Reinforcers obtained by left responses were construed as being analogous to extraneous reinforcement, although they effectively added to whatever true extraneous reinforcement might have been available (McLean \& White, 1983). White et al. demonstrated that the rate of right responses increased as a hyperbolic function of an increasing rate of reinforcers for right responses, as hypothesized by Hernnstein's (1970) law of effect. More important, they showed that across different conditions, increasing the rate of left reinforcers (analogous to $R_{\mathrm{o}}$ ) resulted in a reduction in the rate parameter (half life) of the hyperbola, in accord with the expected effect of $R_{\mathrm{o}}$. In other words, extraneous reinforcement modulates the relation between response rate and reinforcement rate in the main task.

In DMTS, $R_{\mathrm{o}}$ refers to reinforcement for behaviors other than performing in the DMTS task and is not usually scheduled by experimenters. Might an analogous effect of $R_{\mathrm{o}}$ in single schedules be observed in DMTS? In DMTS, the behavior referred to as remembering is measured in terms of its accuracy (or discriminability). We therefore ask whether the accuracy of remembering is influenced by extraneous reinforcement, especially when the reinforcement for DMTS is relatively lean. Experiment 1 tested this possibility by explicitly reinforcing an alternative behavior (see below). By arranging response-independent reinforcement, Experiment 2 tested the possibility that reinforcer delivery alone caused the disruptive effect in Experiment 1. 


\section{EXPERIMENT 1}

In Experiment 1, the probability of reinforcement for correct choices in the DMTS task was varied, with reinforcer probabilities of .2, .4, .7, and .9 arranged over four conditions (and replications). Increasing reinforcer probability was expected to increase discriminability, as had previously been reported by Brown and White (2005) and White and Wixted (1999). The manipulation of interest was the rate of VI reinforcement for center key responses during the retention interval. Three sets of conditions (and replications) were arranged: extinction (EXT), VI $30 \mathrm{sec}$, and VI $15 \mathrm{sec}$, thus varying reinforcer rate in the extraneous task from nothing to lean to rich. The center key reinforcers were treated as the analogue of $R_{\mathrm{o}}$.

The rationale for this arrangement was that the memory task would run concurrently with other, competing tasks, which typically are implicit and not arranged by the experimenter, and that, by making the extraneous task explicit, we would be able to assess the effects of reinforcers obtained in it on memory performance. Ideally, the concurrently available competing task would continue throughout the experimental session, but we scheduled it only during the retention interval for the following two reasons. First, the competing VI schedule was not available during presentation of the sample or during availability of the choice response so that both could occur at the normal rate (in terms of trial completion) and without extending the latency to complete the sample response requirement or the choice response. The latter, in particular, would extend the retention interval and, as a result, arti- factually reduce accuracy. Completion of the sample response requirement and execution of the choice response, which typically take very little time, were essential to completion of a DMTS trial and, in practical terms, are required in order to measure memory performance. If the extraneous task was concurrent with sample presentation and the choice response (thus completing the analogy to extraneous reinforcement), discriminability might well decrease, but so would trial frequency. Second, the competing VI schedule was not arranged in the intertrial interval because we assumed that the behavior of remembering was specific to the DMTS trial. In any case, including the extraneous reinforcement analogue in the intertrial interval in a conditional discrimination involving a timing response makes little difference, as compared with including it only in the trial (Bizo \& White, 1995).

\section{Method}

\section{Subjects}

Four experimentally experienced adult homing pigeons (Columba livia), E1-E4, were housed in individual cages in a naturally lit room supplemented by incandescent light on a 12:12-h light:dark cycle. Water and grit were freely available in living cages. After each experimental session, the pigeons were given enough corn, wheat, and maple peas to maintain them at $85 \% \pm 10 \mathrm{~g}$ of their free-feeding weights (measured in midsummer). If a pigeon's weight fell outside of this range, it did not participate in the day's experimental session. Pigeons E1-E3 participated in 24 conditions, whereas E4 was added after the 9th condition and was ill for the last 2 (see Table 1).

\section{Apparatus}

The four experimental chambers (Med Associates, Inc.) were $29.5 \mathrm{~cm}$ high, $29.5 \mathrm{~cm}$ wide, and $24.5 \mathrm{~cm}$ deep. They had grid floors,

Table 1

Center Key Variable Interval (VI) Schedules and Reinforcement Probabilities by Experimental Condition

\begin{tabular}{cclcccc}
\hline \multirow{2}{*}{$\begin{array}{c}\text { Ordinal Position } \\
\text { of Condition }\end{array}$} & $\begin{array}{c}\text { Reinforcement } \\
\text { Probability }\end{array}$ & Center Key VI & \multicolumn{4}{c}{ Number of Sessions } \\
\cline { 4 - 8 } 1 & .5 & Schedule & E1 & E2 & E3 & E4 \\
\hline $2^{*}$ & .5 & VI $15 \mathrm{sec}$ & 16 & 15 & 16 & - \\
3 & .2 & VI 15 sec & 16 & 16 & 16 & - \\
4 & .2 & VI 30 sec & 16 & 16 & 17 & - \\
5 & .2 & EXT & 17 & 17 & 17 & - \\
6 & .5 & EXT & 17 & 17 & 17 & - \\
7 & .9 & EXT & 17 & 17 & 17 & - \\
8 & .7 & EXT & 20 & 20 & 20 & - \\
9 & .9 & VI 30 sec & 19 & 19 & 19 & 20 \\
10 & .7 & VI 30 sec & 21 & 20 & 19 & 18 \\
11 & .9 & VI 15 sec & 26 & 21 & 27 & 27 \\
$12^{*}$ & .7 & VI 15 sec & 31 & 27 & 30 & 30 \\
13 & .2 & VI 30 sec & 20 & 20 & 20 & 20 \\
14 & .2 & VI 15 sec & 15 & 15 & 15 & 15 \\
15 & .2 & EXT & 20 & 19 & 20 & 20 \\
16 & .5 & VI 30 sec & 18 & 18 & 18 & 18 \\
17 & .5 & EXT & 16 & 16 & 16 & 16 \\
18 & .9 & VI 15 sec & 15 & 19 & 19 & 23 \\
19 & .9 & VI 30 sec & 16 & 19 & 18 & 22 \\
20 & .9 & EXT & 17 & 19 & 20 & 21 \\
21 & .7 & EXT & 20 & 20 & 20 & 19 \\
22 & .5 & VI 15 sec & 17 & 17 & 17 & 17 \\
23 & .7 & VI 30 sec & 16 & 19 & 20 & - \\
24 & .9 & 21 & 23 & 25 & - \\
\hline
\end{tabular}

${ }^{*}$ More sessions were conducted, due to equipment failure. 
opaque walls, and transparent plastic side doors. Partitions obscured chambers from each other in the dark experimental room, and extractor fans provided masking noise. Each chamber contained three Plexiglas response keys $2.1 \mathrm{~cm}$ in diameter, recessed into the front wall by $1 \mathrm{~cm}$ and mounted $21 \mathrm{~cm}$ above the grid floor. Side keys were $6 \mathrm{~cm}$ either side of the center key. They could be illuminated red or green. The center key could also be illuminated white. When any illuminated key was pecked with sufficient force, it activated a relay that provided the subjects with auditory feedback. Wheat reinforcers could be delivered via a hopper located in an aperture $12.5 \mathrm{~cm}$ below the center key. The aperture was $6 \mathrm{~cm}$ wide and $4.5 \mathrm{~cm}$ high. Two lamps above the hopper were illuminated when wheat was available. The lights, hopper, and recording of keypecks to illuminated keys were all administered by an IBM-compatible PC running Med-PC software and connected to Med-PC interfacing.

\section{Procedure}

Twenty-four experimental conditions were conducted. Preliminary training was not necessary, given the pigeons' prior experience in DMTS. Over the 24 conditions, two factors were manipulated. The first was the probability of reinforcement for correct matching. The second was the VI schedule of reinforcement for pecking the white center key during the delay interval (either EXT, VI $30 \mathrm{sec}$, or VI $15 \mathrm{sec}$ ). We will refer to this as center key reinforcement. Table 1 shows the order in which the conditions were run. All the conditions were replicated at least once, except for Pigeon E4, since it entered the experiment part way through.

Each pigeon was tested at the same time $( \pm 1 \mathrm{~h})$ and in the same chamber every day. Daily sessions consisted of 97 trials for each pigeon, but data from the first trial were never analyzed, and responses in that trial were never reinforced. A pigeon's session was terminated if it did not finish all 97 trials in $50 \mathrm{~min}$. Each trial began when a red or green sample was presented on the center key. Once this had been pecked five times (FR 5), the retention interval commenced and lasted for $0.2,1,4$, or $12 \mathrm{sec}$. During the retention interval, the center key was illuminated white, and pecks to it were reinforced with 2.5 -sec access to wheat according to EXT, VI 15-sec, or VI 30 -sec schedules in different conditions. These constant-probability VI schedules operated solely within the retention interval, and their timing was reset only when reinforcers were delivered. They were constructed according to the progression described by Fleshler and Hoffman (1962).
Following the retention interval, the center keylight was extinguished, and the side keys were illuminated, one red and one green. A single response to the side key color that matched the sample was reinforced with $3-\mathrm{sec}$ access to wheat, with a probability of .2, .5, .7, or .9 in different conditions (see Table 1). Nonmatching responses produced a 3-sec blackout. A completely dark 15 -sec intertrial interval then commenced. The order and frequency of the different delay intervals, sample colors, and side key colors was fully counterbalanced within each experimental session (disregarding the first trial), so that each combination occurred equally often. For each session with each pigeon, all choice responses were recorded, as was the number of pecks to the white center key and its associated reinforcers. Each condition was planned to continue for 15 sessions. Because conditions were changed for all the pigeons at the same time and because some pigeons were outside of their prescribed weight range more often than others, the number of sessions per condition differed between birds. In addition, more sessions were conducted if there was an equipment failure, if a session was disrupted, or if a pigeon's session followed 3 or more consecutive days of nonparticipation for being outside of its prescribed weight range. The number of sessions for each pigeon in each condition is shown in Table 1.

\section{Results and Discussion}

For each pigeon, response counts were summed over the last 7 days of each condition. They were separated according to sample stimulus color (red vs. green), choice color (red vs. green), response side (left vs. right), the relationship of the choice color to the prior trial's sample (same vs. different), and retention interval duration $(0.2,1,4$, and $12 \mathrm{sec})$. For each pigeon in each condition, overall proportion-correct remembering accuracy did not significantly increase or decrease over the 7 days of data examined, as measured by the slope of its linear trend. Data were thus considered to be stable, since performance was neither improving nor worsening over days.

Figure 1 shows the proportion of correct responses (i.e., $B_{1} \mid S_{1}$ and $B_{2} \mid S_{2}$ ) averaged over pigeons, replications, and retention interval, and over reinforcer probability (left panel) or center key schedule (right panel). Along with a
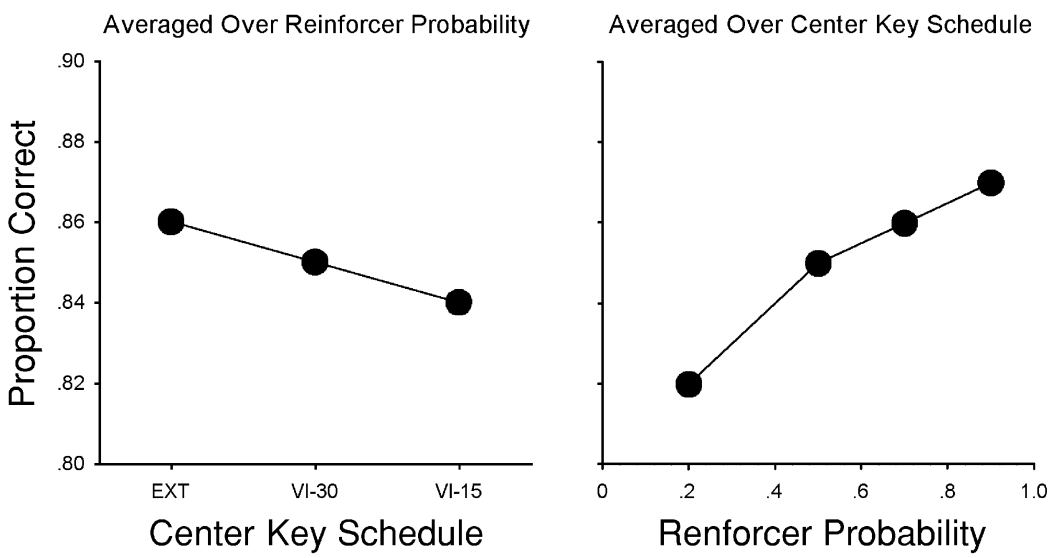

Figure 1. Average proportion-correct accuracy for each center key reinforcement schedule (left panel) and each reinforcer probability (right panel) in Experiment 1. Proportions are averaged over pigeon, replication, retention interval, and reinforcer probability (left panel) or center key reinforcement schedule (right panel). 


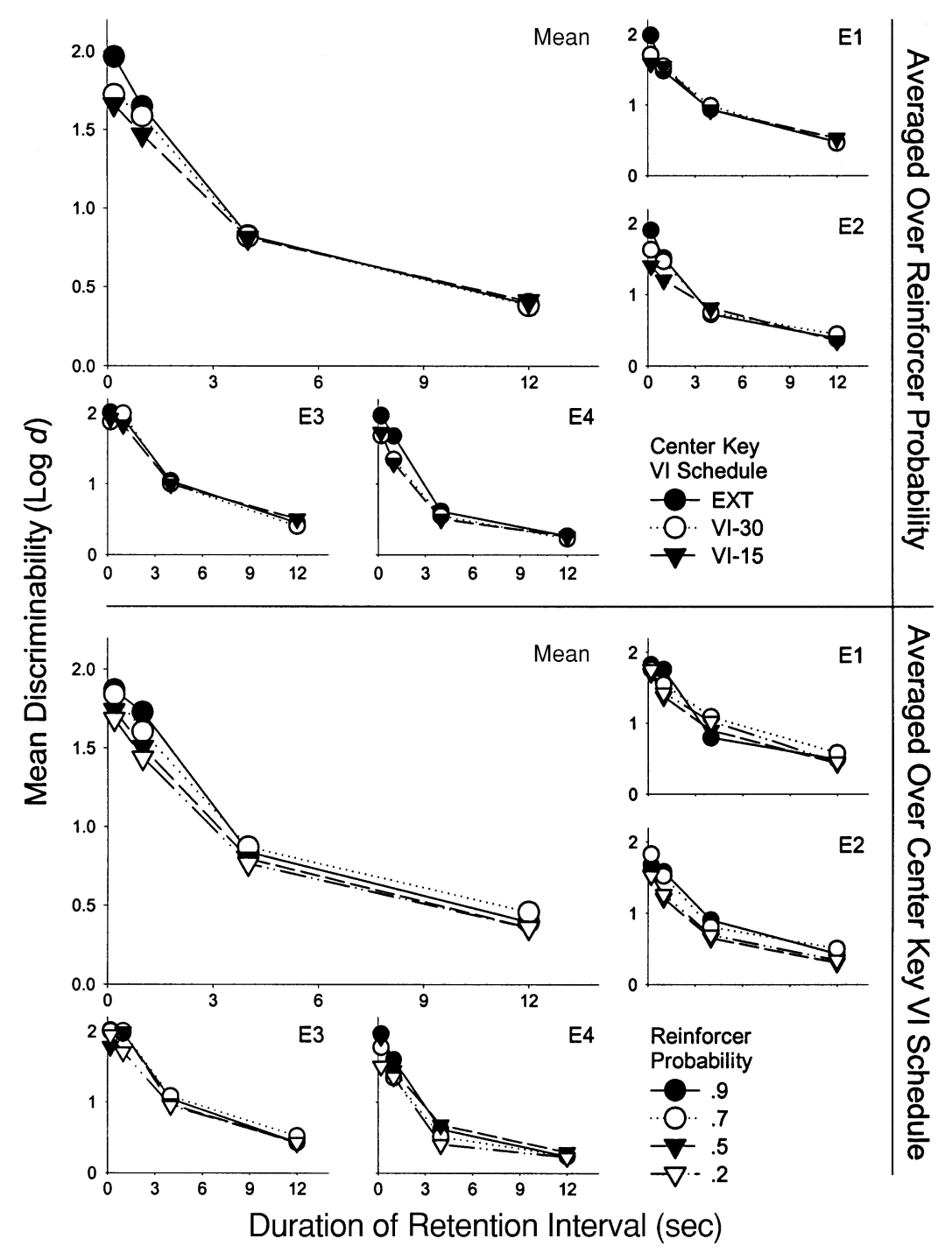

Figure 2. Mean discriminability $(\log d)$ at each retention interval for individual pigeons (peripheral graphs) and their collective means (main graphs) in Experiment 1. The main effect of center key variable-interval (VI) schedule (top panel) is shown by averaging over reinforcer probability, whereas the main effect of reinforcer probability (bottom panel) is shown by averaging over center key VI schedule.

two-factor (reinforcer probability $\times$ center key VI schedule) repeated measures analysis of variance (ANOVA), Figure 1 shows that as the rate of VI reinforcement for center key pecking increased, overall proportion-correct matching decreased, although not significantly at $\alpha=.05$ $[F(2,33)=2.79, p=.076]$. It also shows that as the reinforcer probability for correct matching increased, the proportion correct increased $[F(3,33)=8.05, p<.001]$. These variables did not interact $[F(6,33)<1]$.

Although proportion correct is useful for assessing large differences in accuracy, it is subject to ceiling effects and may be influenced by response biases that arise from preferences to a particular color or side key
(Brown, 2003). In addition, choices may be biased by the reinforced choice on the previous trial (White, Parkinson, Brown, \& Wixted, 2004). In general terms, this proactive interference is manifest as an overall preference toward the choice that matches the prior trial's sample (Grant, 1975, 1982; Miyashita, Nakajima, \& Imada, 2000; Roberts \& Grant, 1976). Therefore, a bias-free measure of discrimination, $\log d$ (Davison \& Tustin, 1978), was used in which all the biases above were treated according to Davison and Tustin's treatment of response bias.

For each pigeon, $\log d$ was calculated at each retention interval of each condition but was averaged over replications. Averaging was not possible for Pigeon E4, because 
Table 2

Curve-Fitting Parameters for Each Pigeon in Each Condition in Experiment 1

\begin{tabular}{|c|c|c|c|c|c|c|c|c|c|}
\hline \multicolumn{2}{|c|}{ Condition } & \multicolumn{8}{|c|}{ Pigeon } \\
\hline \multirow{2}{*}{$\begin{array}{l}\text { Reinforcement } \\
\text { Probability }\end{array}$} & \multirow[b]{2}{*}{ Center Key Schedule } & \multicolumn{2}{|c|}{ E1 } & \multicolumn{2}{|c|}{ E2 } & \multicolumn{2}{|c|}{ E3 } & \multicolumn{2}{|c|}{ E4 } \\
\hline & & $\log d_{0}$ & $b$ & $\log d_{0}$ & $b$ & $\log d_{0}$ & $b$ & $\log d_{0}$ & $b$ \\
\hline \multicolumn{10}{|c|}{ First Run } \\
\hline \multirow[t]{3}{*}{.2} & EXT & 1.924 & 0.190 & 1.405 & 0.236 & 2.117 & 0.192 & 1.569 & 0.287 \\
\hline & VI 30 & 1.772 & 0.445 & 1.838 & 0.199 & 1.867 & 0.238 & 1.691 & 0.287 \\
\hline & VI 15 & 1.509 & 0.374 & 1.523 & 0.203 & 1.575 & 0.180 & 1.739 & 0.314 \\
\hline \multirow[t]{3}{*}{.5} & EXT & 1.782 & 0.181 & 2.238 & 0.358 & 1.770 & 0.143 & 1.975 & 0.256 \\
\hline & VI 30 & 1.503 & 0.113 & 1.395 & 0.218 & 1.758 & 0.143 & 2.040 & 0.309 \\
\hline & VI 15 & 1.174 & 0.053 & 1.446 & 0.191 & 1.842 & 0.232 & 1.875 & 0.205 \\
\hline \multirow[t]{3}{*}{.7} & EXT & 2.093 & 0.228 & 2.336 & 0.183 & 2.129 & 0.171 & 2.386 & 0.259 \\
\hline & VI 30 & 1.778 & 0.129 & 2.151 & 0.222 & 2.241 & 0.184 & 1.647 & 0.368 \\
\hline & VI 15 & 1.958 & 0.071 & 1.260 & 0.106 & 2.105 & 0.105 & 1.568 & 0.334 \\
\hline \multirow[t]{3}{*}{.9} & EXT & 2.223 & 0.259 & 2.302 & 0.209 & 2.101 & 0.170 & 2.492 & 0.291 \\
\hline & VI 30 & 1.921 & 0.194 & 2.243 & 0.163 & 2.043 & 0.161 & 1.710 & 0.170 \\
\hline & VI 15 & 1.876 & 0.123 & 1.343 & 0.091 & 2.158 & 0.208 & 2.090 & 0.422 \\
\hline \multicolumn{10}{|c|}{ Replication Conditions } \\
\hline \multirow[t]{3}{*}{.2} & EXT & 1.858 & 0.086 & 2.153 & 0.312 & 1.929 & 0.087 & & \\
\hline & VI 30 & 1.954 & 0.056 & 0.924 & 0.013 & 2.082 & 0.141 & & \\
\hline & VI 15 & 1.765 & 0.079 & 1.469 & 0.127 & 2.299 & 0.138 & & \\
\hline \multirow[t]{3}{*}{.5} & EXT & 1.734 & 0.149 & 1.501 & 0.258 & 2.287 & 0.145 & & \\
\hline & VI 30 & 1.993 & 0.223 & 1.612 & 0.171 & 2.290 & 0.143 & & \\
\hline & VI 15 & 1.867 & 0.136 & 1.218 & 0.076 & 2.051 & 0.097 & & \\
\hline \multirow[t]{4}{*}{.7} & EXT & 1.676 & 0.076 & 1.824 & 0.106 & 2.277 & 0.140 & & \\
\hline & VI 30 & 1.733 & 0.079 & 1.582 & 0.139 & 1.973 & 0.097 & & \\
\hline & VI 15 & 1.364 & 0.127 & 1.600 & 0.130 & 2.034 & 0.142 & & \\
\hline & EXT & 2.091 & 0.199 & 1.657 & 0.127 & 2.316 & 0.171 & & \\
\hline \multirow[t]{2}{*}{.9} & VI 30 & 1.653 & 0.107 & 1.510 & 0.088 & 2.313 & 0.142 & & \\
\hline & VI 15 & 1.835 & 0.153 & 1.357 & 0.112 & 1.989 & 0.098 & & \\
\hline
\end{tabular}

Note-Conditions were not replicated for Pigeon E4, because it joined the experiment partway through.

it experienced each condition only once. These data were then submitted to a three-factor (reinforcer probability $\times$ center key VI schedule $\times$ retention interval duration) repeated measures ANOVA. We will not report $F$ ratios for the effect of retention interval and its interactions, because variance uniformly decreased as discriminability fell over increasing retention interval length, thus violating the fundamental ANOVA assumption of homogeneity of variance. Nevertheless, Figure 2 shows that $\log d$ was substantially reduced with increasing retention interval duration for each pigeon in every condition.

Figure 2 shows how the duration of the retention interval, the reinforcer probability and the center key VI schedule affected $\log d$. For clarity, data are shown averaged over reinforcer probability (top panel) and center key VI schedule (bottom panel). There was no statistically significant interaction between reinforcer probability and center key reinforcement $[F(6,33)<1]$ and no interaction with retention interval. The top panel of Figure 2 shows that as the frequency of VI reinforcement for center key pecking increased, discriminability decreased $[F(2,33)=$ $5.45, p<.01]$. This is most obvious at the shortest retention intervals and for all the pigeons except E3. The bottom panel shows that as reinforcer probability increased, discriminability also increased $[F(3,33)=5.45, p<.01]$ by a similar amount at each retention interval.

\section{Analysis Using Curve Fits}

Negative exponential functions (Equation 2) were fit to each pigeon's data in each condition, using a least-squares technique. This allowed each bird's performance to be summarized by just two parameters per condition: the $y$ intercept, or initial discriminability $\left(\log d_{0}\right)$, and the slope, or rate of forgetting $(b)$. A further advantage to analyzing curve-fitting parameters is that in the present experiment, they adhered to the fundamental ANOVA assumption that variance is homogeneous. Curve-fitting parameters for each pigeon in each condition are shown in Table 2 . The mean variance accounted for was $92 \%$, indicating good fits. For subsequent analyses, the parameter values for individual conditions were averaged over replications. Example curve fits to mean discriminability values in each condition are shown in Figure 3 (but note that fits to mean data do not necessarily represent the mean of individual fits).

Initial discriminability. Means of the initial discriminability $\left(\log d_{0}\right)$ parameters for the best-fitting functions for each pigeon in each condition are plotted in Figure 4. These data were submitted to a two-factor repeated measures ANOVA (reinforcer probability $\times$ center key VI schedule). Increasing the rate of reinforcement for center key pecking reduced initial discriminability $[F(12,33)=$ $12.30, p<.001]$. Furthermore, increasing the probability 


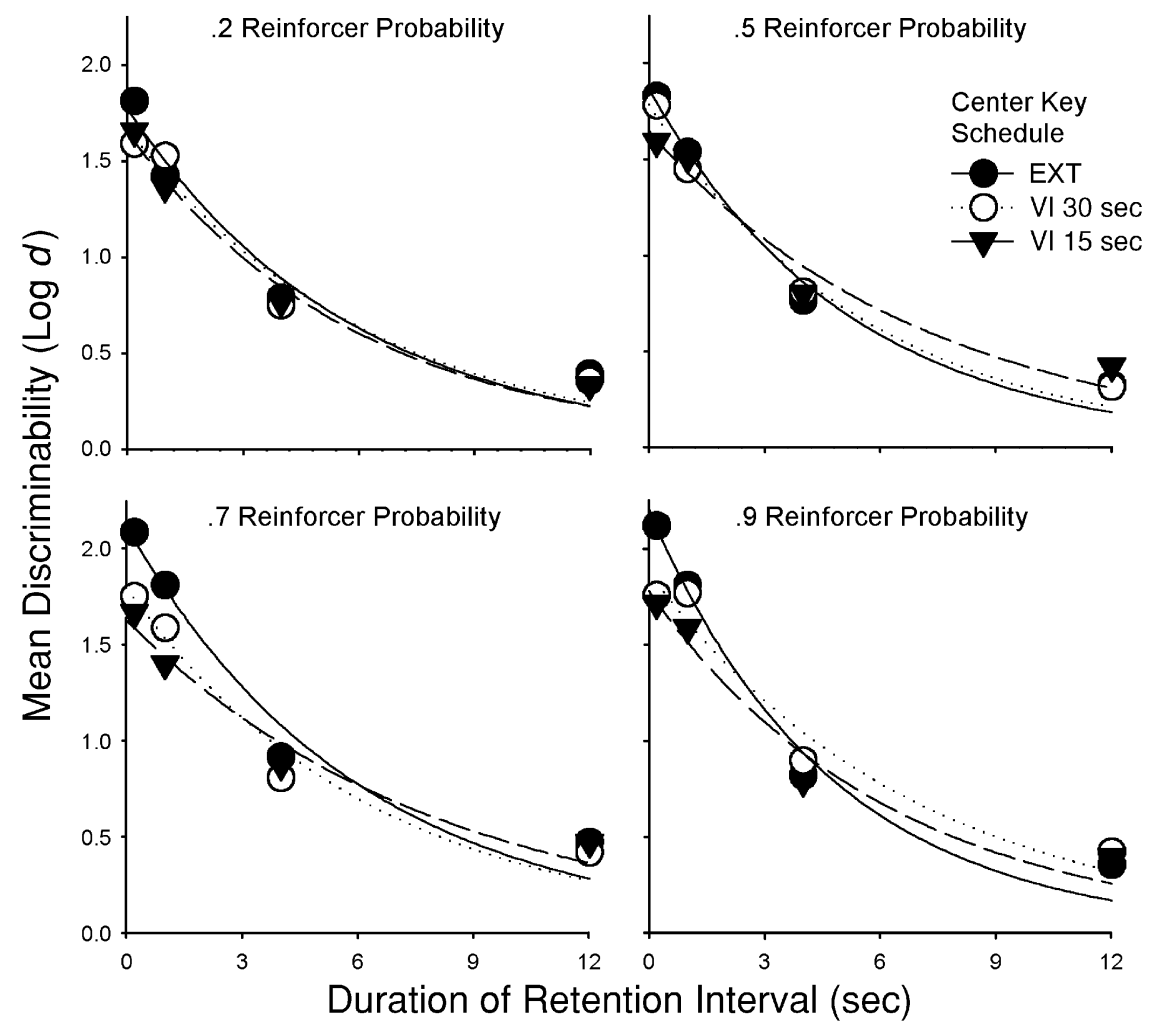

Figure 3. Example negative exponential curve fits to mean discriminability $(\log d)$ values in each condition in Experiment 1. Data are shown for reinforcer probabilities of .2 (top left), .5 (top right), 7 (bottom left), and .9 (bottom right). Within each graph, data are shown separately for extinction (EXT; filled circles, solid lines), variable-interval (VI) 30-sec (open circles, dotted lines), and VI 15-sec (filled triangles, dashed lines) center key reinforcement schedules.

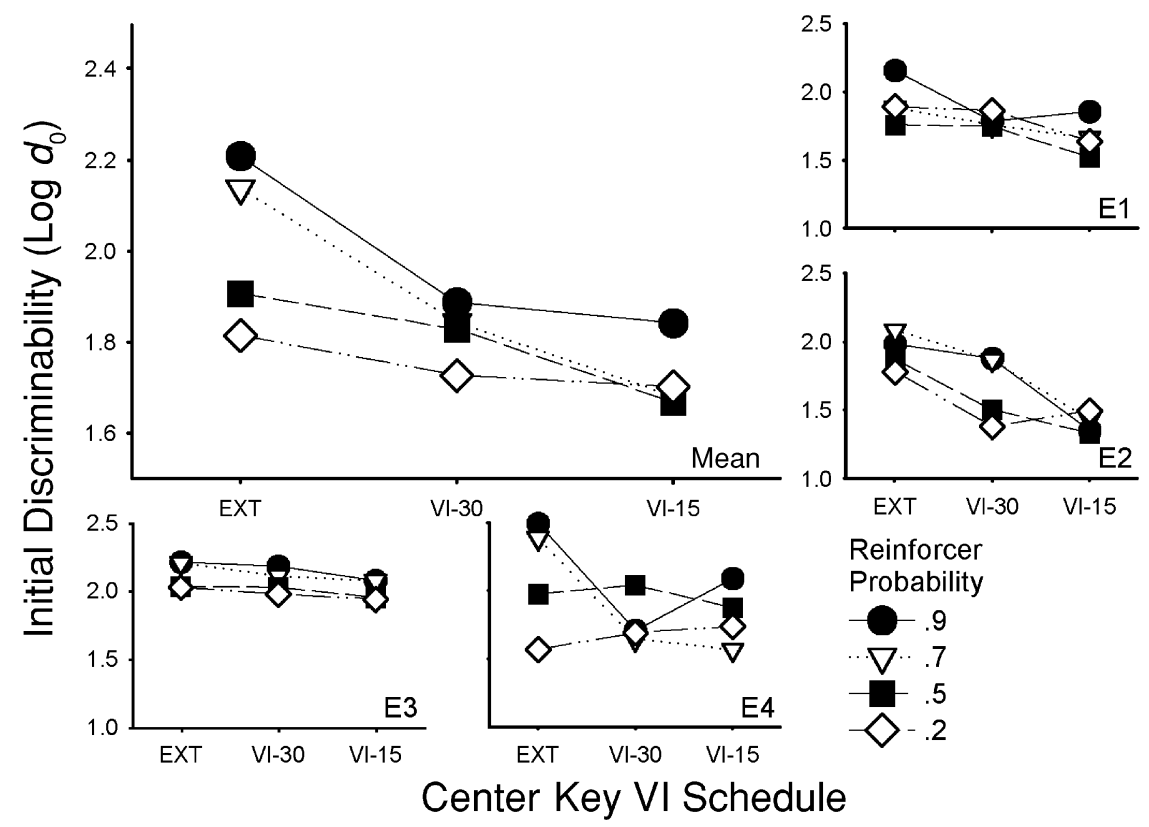

Figure 4. Mean fitted initial discriminability $\left(\log d_{0}\right)$ parameters for each center key reinforcement schedule (extinction [EXT], variable interval [VI] 30 sec, or VI 15 sec) in Experiment 1, based on the values for individual pigeons in Table 2. Values are shown for individuals (peripheral graphs) and averaged over pigeons (main graph). Within each graph, parameters are shown for reinforcer probabilities of .9 (filled circles, solid lines), 7 (open triangles, dotted lines), .5 (filled squares, dashed lines), and .2 (open diamonds, dotted and dashed lines). 


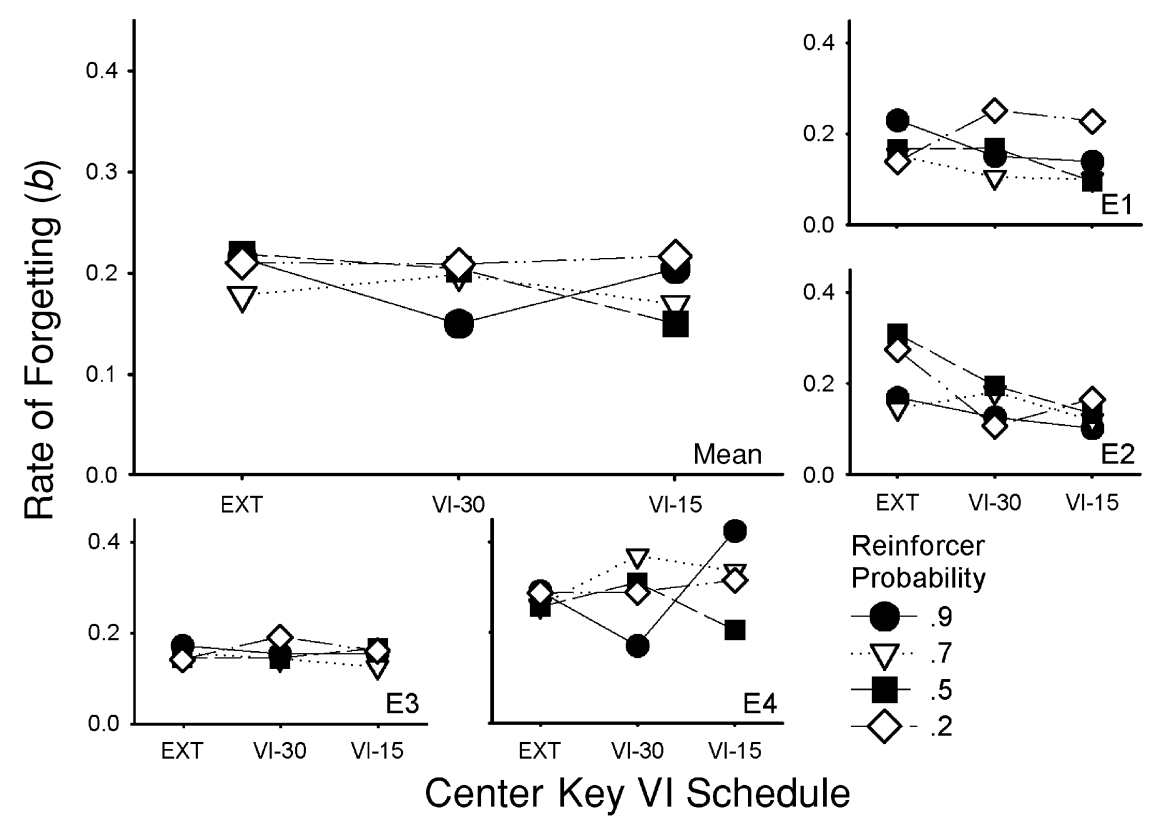

Figure 5. Mean fitted rate of forgetting $(b)$ parameters for each center key reinforcement schedule (extinction [EXT], variable interval [VI] 30 sec, VI 15 sec) in Experiment 1, based on values for individual pigeons in Table 2. Values are shown for individuals (peripheral graphs) and averaged over pigeons (main graph). Within each graph, parameters are shown for reinforcer probabilities of .9 (filled circles, solid lines), .7 (open triangles, dotted lines), .5 (filled squares, dashed lines), and .2 (open diamonds, dotted and dashed lines).

of reinforcement for correct matching increased initial discriminability $[F(3,33)=4.24, p<.05]$. The effect of reinforcer probability was similar regardless of the amount of center key reinforcement, as indicated by the absence of a significant interaction between these variables $[F(6,33)=1.02$, n.s. $]$.

Rate of forgetting. Figures 1 and 2 suggested that changing the reinforcement for center key pecking might have had stronger effects at short than at long retention intervals. This is the pattern expected when there is a reduction in initial discriminability without a change in rate of forgetting (White, 2001). Figure 5 and a two-factor repeated measures ANOVA show that neither reinforcer probability $[F(3,33)<1]$ nor center key reinforcement schedule $[F(2,33)<1]$, in any combination $[F(6,33)=$ 1.01 , n.s.], had consistent effect on the rate of forgetting.

\section{Center Key Pecking}

Clearly, center key VI reinforcement affected matching accuracy. We also examined whether the rate of reinforcement for correct matching influenced center key pecking. For each pigeon, we counted the total number of center key pecks during all the trials over the last 7 days of each condition. The number of pecks was averaged over replications of the same condition, when applicable. Figure 6 shows that the number of pecks to the center key increased as the center key reinforcement increased $[F(2,33)=10.42, p<.001]$. Interestingly, the probability of reinforcement for correct matching also affected the amount of center key pecking $[F(3,33)=3.16, p<.05]$, but in an unusual pattern. For all values of center key reinforcement, the number of center key pecks was highest with a reinforcer probability of .2 , then .9 , and then .5 . When the reinforcer probability was .7 , center key pecking appeared to be more sensitive to the amount of center key reinforcement. As a consequence, the reinforcer probability of. .7 appears to be less systematically related to the other reinforcer probabilities in Figure 6.

\section{Summary}

Experiment 1 demonstrated that increasing the overall probability of reinforcement for correct matching to $S_{1}$ and $S_{2}$ increased initial discriminability, $\log d_{0}$. More important, Experiment 1 showed that increasing the reinforcement for an analogue extraneous behavior, $R_{\mathrm{o}}$, reduced $\log d_{0}$. We shall, however, defer further discussion of our finding until we have addressed a potential confound in the experiment. Instead of being the result of reinforcement contingencies for center key pecking, scheduling reinforcers on the center key might have reduced discriminability simply by allowing disruptive feeding behaviors and stimuli such as hopper illumination to occur in the retention interval. In Experiment 2, we investigated this possibility.

\section{EXPERIMENT 2}

When food is presented during the retention interval or when the retention interval is illuminated, discriminability is substantially reduced (Jans \& Catania, 1980; Roberts \& 


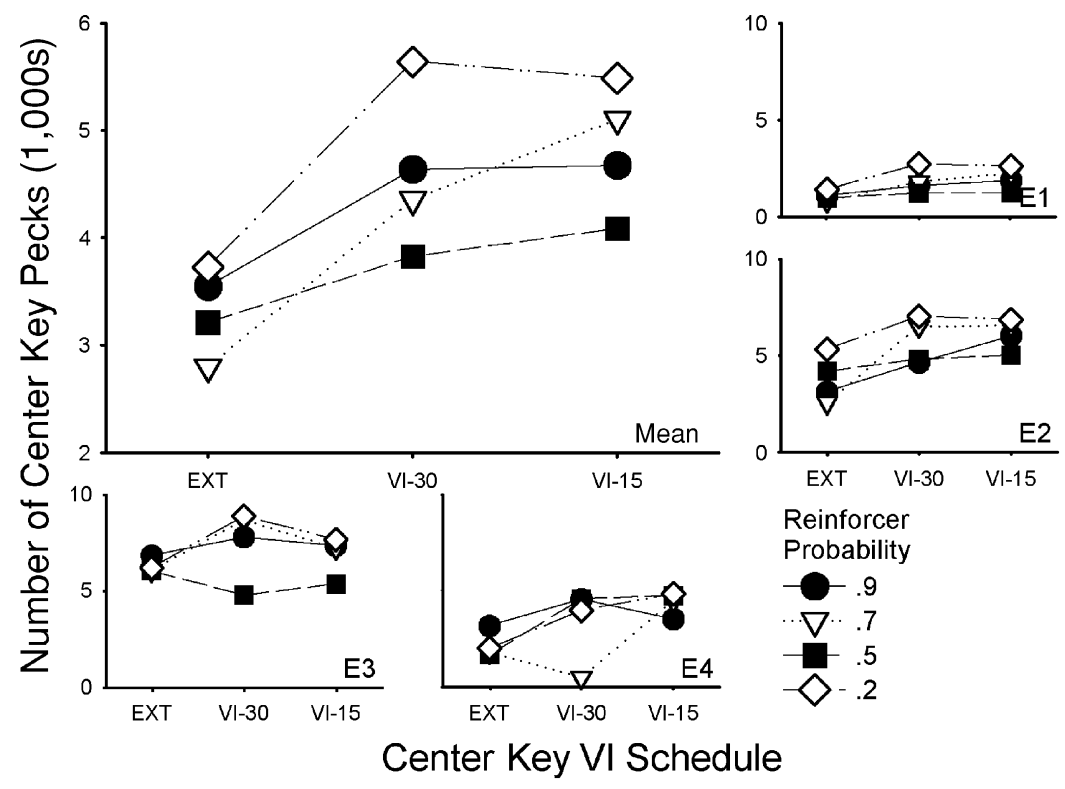

Figure 6. Mean number of center key pecks for each center key reinforcement schedule (extinction [EXT], variable interval [VI] 30 sec, VI 15 sec) in Experiment 1. Values are shown for individuals (peripheral graphs) and averaged over pigeons (main graph). Within each graph, parameters are shown for reinforcer probabilities of .9 (filled circles, solid lines), .7 (open triangles, dotted lines), .5 (filled squares, dashed lines), and .2 (open diamonds, dotted and dashed lines).

Grant, 1978). This disruptive effect is typically treated as an instance of retroactive interference and is manifest as an increase in rate of forgetting (White, 1985), although initial discriminability is reduced when the duration of the interfering event, such as houselight illumination, is held constant (Harper \& White, 1997). It is, therefore, possible that the effects of center key reinforcement observed in Experiment 1 were merely the result of center key illumination, feeding, or some disrupter that accompanied the delivery of food. Experiment 2 tested this possibility by explicitly comparing the effects of scheduling food on a response-contingent VI schedule (as in Experiment 1) with those of presenting food freely on a response-independent variable-time (VT) schedule. The VI conditions in Experiment 2 offered a partial replication of Experiment 1. In Experiment 2, we demonstrated that scheduling free food in the retention interval does not affect initial discriminability in the same way as food delivered on VI schedules, thus suggesting that the effects observed in Experiment 1 were not caused by the mere presentation of food or center key illumination.

\section{Method}

\section{Subjects and Apparatus}

Five adult homing pigeons (Columba livia), N1-N5, that were experienced in DMTS and similar discrimination tasks were housed and treated as in Experiment 1. Five experimental chambers were used. These were the same four chambers as those in Experiment 1, plus one identical chamber. Otherwise, the apparatus was the same as that in Experiment 1. Pigeon N2 died before the last two conditions were run.

\section{Procedure}

The daily procedure was the same as that in Experiment 1 . The only difference was that, in some conditions, reinforcers during the retention interval were provided on a response-independent VT schedule, rather than being dependent on center key pecking. Both types of schedule generate a similar amount of feeding during the retention interval. The order of conditions is shown in Table 3. The pigeons were exposed to VT reinforcers during the retention interval for 6 months prior to the start of the experiment. For the experimental conditions, all VT schedules were run first, because the VI schedules generated a high number of pecks on the center key, possibly making it potentially difficult for the pigeons to discriminate between VT and VI schedules in subsequent conditions. Owing to the prior training with VT schedules, the pigeons emitted few responses on the center key in the VT conditions. The full list of conditions, including the number of sessions for each pigeon, is shown in Table 3. Data were collected as in Experiment 1.

\section{Results and Discussion}

Data were analyzed as in Experiment 1, with four exceptions. First, there were fewer conditions and no replications over which to average data. Second, schedule type (VI vs. VT) was an additional factor in every ANOVA. Third, Pigeon N2 was excluded from all ANOVAs because it died before completing the experiment. (But note that when it was included in the analysis using average data, the same conclusions applied.) Fourth, conditions in which there was no reinforcement for center key pecking were excluded from ANOVAs because the difference between them was only nominal: They were the same condition in VI and VT (see Table 3). As such, an ANOVA that included extinction schedules would necessarily in- 
Table 3

\begin{tabular}{|c|c|c|c|c|c|c|c|}
\hline \multirow{3}{*}{$\begin{array}{l}\text { Ordinal Position } \\
\text { of Condition }\end{array}$} & \multicolumn{7}{|c|}{$\begin{array}{l}\text { Variable Time (VT) or Center Key Schedules and } \\
\text { Reinforcement Probabilities by Condition }\end{array}$} \\
\hline & \multirow{2}{*}{$\begin{array}{l}\text { Reinforcement } \\
\text { Probability }\end{array}$} & \multirow{2}{*}{$\begin{array}{l}\text { VT or Center } \\
\text { Key Schedule }\end{array}$} & \multicolumn{5}{|c|}{ Number of Sessions } \\
\hline & & & N1 & $\mathrm{N} 2$ & N3 & N4 & N5 \\
\hline 1 & .9 & EXT & 27 & 27 & 21 & 27 & 15 \\
\hline 2 & .9 & VT $30 \mathrm{sec}$ & 29 & 29 & 28 & 28 & 18 \\
\hline 3 & .9 & VT $15 \mathrm{sec}$ & 28 & 28 & 22 & 27 & 14 \\
\hline 4 & .5 & EXT & 19 & 19 & 18 & 19 & 17 \\
\hline 5 & .5 & VT $15 \mathrm{sec}$ & 26 & 26 & 23 & 25 & 17 \\
\hline 6 & .5 & VT $30 \mathrm{sec}$ & 25 & 25 & 23 & 24 & 16 \\
\hline $7^{*}$ & .5 & VI $30 \mathrm{sec}$ & 25 & 24 & 24 & 25 & 16 \\
\hline 8 & .5 & VI $15 \mathrm{sec}$ & 30 & 29 & 27 & 31 & 16 \\
\hline 9 & 9 & VI $30 \mathrm{sec}$ & 34 & $-\dagger$ & 28 & 34 & 18 \\
\hline $10 \ddagger$ & .9 & VI $15 \mathrm{sec}$ & 58 & - & 50 & 57 & 29 \\
\hline
\end{tabular}

${ }^{*}$ Conditions changed from VT to VI schedules at Condition 7. †Pigeon N2 died during Condition 9. $¥$ More sessions were conducted in Condition 10 because of a series of equipment failures.

corporate duplicate data, thus generating artificially low variance. Our exclusions err on the conservative side.

Figure 7 shows discriminability data collapsed over reinforcer probability. Such collapsing is justified by the absence of significant interactions involving reinforcer probability [probability $\times$ schedule type, $F(1,18)=1.78$, n.s.; probability $\times$ schedule, $F(1,18)<1$; and all higher order interactions involving probability]. The crucial result is that when the schedule of retention interval reinforcement became richer, discriminability fell $[F(1,18)=$ $6.26, p<.05]$, but only when reinforcement was contingent on pecking the center key $[F(1,18)=4.83, p<.05]$. That is, changing the richness of the retention interval VT schedule did not affect discriminability. Unlike in Experiment 1 , there was no main effect of reinforcer probability $[F(1,18)<1]$. This is likely to be the result of using a narrower range of reinforcer probabilities (.5-.9) than in Experiment $1(.2-.9)$.

\section{Analysis of Curve-Fitting Parameters}

Initial discriminability. As in Experiment 1, negative exponential curves were fit to discriminability data. All the curve-fitting parameters are shown in Table 4. The mean variance accounted for was $94 \%$, indicating good fits overall. Initial discriminability $\left(\log d_{0}\right)$ values from those curve fits are plotted in Figure 8, collapsed over reinforcer probability. Confirming the analysis of discriminability values, it shows that making the retention interval reinforcement schedule richer reduced initial discriminability $[F(1,18)=5.85, p<.05]$, but only when the reinforcement was contingent on center key pecking $[F(1,18)=5.89, p<.05]$.

Rate of forgetting. Figure 9 shows that the rate of forgetting was not significantly affected by the schedule type $[F(1,3)<1]$ or its richness $[F(1,18)<1]$ in any combination $[F(1,18)<1]$. It was, however, affected by reinforcer probability, but only when retention interval reinforcement was response independent $[F(1,18)=6.40, p<$ $.05]$. Post hoc least significant difference tests confirmed that this was the result of a very high rate of forgetting in one condition only (VT $15 \mathrm{sec}$, with a reinforcer probability of .9). In that condition, the high rate of forgetting was extremely high for 1 pigeon only (N5). Our conclusion, therefore, is that there was no overall effect on the rate of forgetting, as in Experiment 1.

\section{Center Key Pecking}

Figure 10 shows that the number of center key pecks was about the same when response-independent reinforcers were delivered within the retention interval at different rates. When those reinforcers were contingent on center key pecking, however, the number of pecks to the center key increased with increasing reinforcement rate, as in Experiment $1[F(1,3)=17.92, p<.05]$.

\section{Summary}

Experiment 2 confirmed that occasional reinforcers presented during the retention interval affected initial discriminability in DMTS, but only when they were contingent on center key pecking. We therefore conclude that when increased reinforcement for an extraneous behavior reduced initial discriminability, the effect was not due to the mere presentation of food or center key illumination during the retention interval. Response contingency was decisive.

\section{GENERAL DISCUSSION}

The present experiments demonstrated that initial discriminability in DMTS decreased when the rate of reinforcement for an extraneous behavior, center key pecking during the retention interval, was increased. There was no consistent effect on the rate of forgetting, and the effect on initial discriminability was not due to the mere presentation of food or center key illumination. That is, initial discriminability was reduced by extraneous reinforcement only when it was contingent on center key pecking. Lowering the overall probability of reinforcement for correct matching-to-sample also reduced initial discriminability. Not only was matching accuracy determined by the rate of 


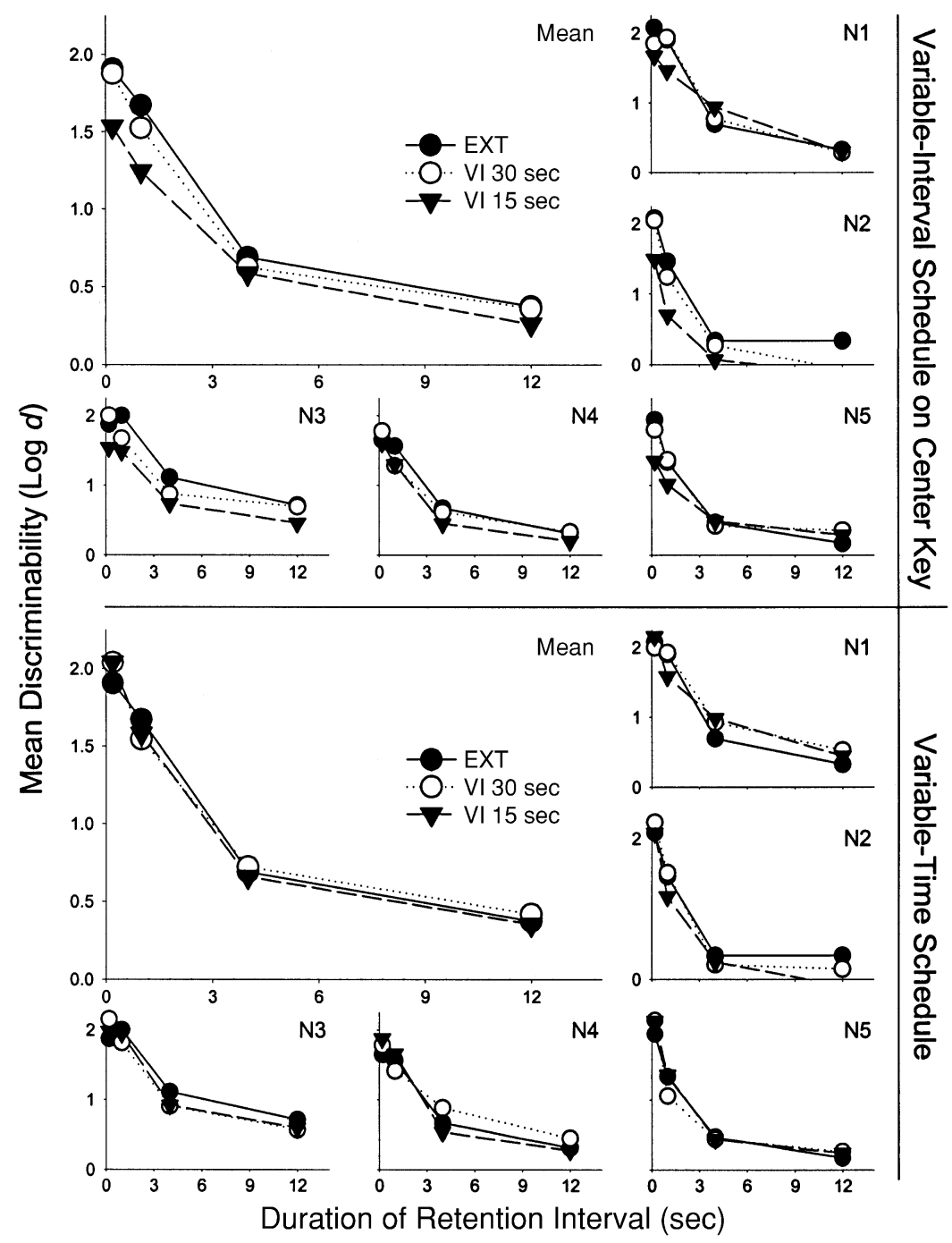

Figure 7. Mean discriminability $(\log d)$ at each retention interval for each variableinterval (VI) schedule (top panel) and each response-independent variable-time (VT) schedule (bottom panel) in Experiment 2. Data are averaged over reinforcer probabilities (.5 and .9) and are shown for each pigeon (peripheral graphs) and their collective mean (main graphs). Pigeon $\mathbf{N} 2$ contributed data only from conditions with a reinforcer probability of .5, because it died before completing VI 30-sec and VI 15-sec conditions in which the reinforcer probability was .9. Note that extinction (EXT) conditions for VI and VT are the same, using the same data.

Table 4

Curve-Fitting Parameters for Each Pigeon in Each Condition in Experiment 2

\begin{tabular}{|c|c|c|c|c|c|c|c|c|c|c|c|}
\hline \multicolumn{2}{|c|}{ Condition } & \multirow{2}{*}{\multicolumn{2}{|c|}{ N1 }} & \multirow{2}{*}{\multicolumn{2}{|c|}{$\mathrm{N} 2$}} & \multirow{2}{*}{\multicolumn{2}{|c|}{ N3 }} & & & & \\
\hline \multirow{2}{*}{$\begin{array}{l}\text { Reinforcement } \\
\text { Probability }\end{array}$} & \multirow{2}{*}{$\begin{array}{l}\text { Center Key } \\
\text { Schedule }\end{array}$} & & & & & & & \multicolumn{2}{|c|}{ N4 } & \multicolumn{2}{|c|}{ N5 } \\
\hline & & $\log d_{0}$ & $b$ & $\log d_{0}$ & $b$ & $\log d_{0}$ & $\mathrm{~b}$ & $\log d_{0}$ & $b$ & $\log d_{0}$ & $b$ \\
\hline \multirow[t]{5}{*}{.5} & EXT & 1.326 & 0.467 & 1.511 & 0.561 & 2.022 & 0.209 & 1.354 & 0.333 & 2.174 & 0.504 \\
\hline & VT 30 & 1.948 & 0.107 & 2.522 & 0.554 & 2.037 & 0.146 & 1.668 & 0.077 & 2.018 & 0.336 \\
\hline & VT 15 & 2.111 & 0.201 & 2.389 & 0.719 & 1.988 & 0.104 & 2.009 & 0.267 & 2.201 & 0.385 \\
\hline & VI 30 & 2.155 & 0.202 & 2.277 & 0.581 & 1.861 & 0.115 & 1.767 & 0.298 & 1.642 & 0.283 \\
\hline & VI 15 & 1.667 & 0.254 & 1.797 & 0.939 & 1.952 & 0.188 & 1.837 & 0.332 & 1.577 & 0.264 \\
\hline \multirow[t]{5}{*}{.9} & EXT & 2.311 & 0.306 & 2.509 & 0.629 & 1.943 & 0.125 & 1.859 & 0.252 & 1.770 & 0.419 \\
\hline & VT 30 & 2.252 & 0.212 & 2.198 & 0.510 & 2.223 & 0.171 & 1.892 & 0.293 & 2.739 & 1.068 \\
\hline & VT 15 & 2.025 & 0.144 & 2.341 & 0.656 & 2.159 & 0.194 & 2.069 & 0.294 & 2.389 & 0.556 \\
\hline & VI 30 & 1.984 & 0.202 & - & - & 1.960 & 0.135 & 1.758 & 0.194 & 2.190 & 0.401 \\
\hline & VI 15 & 1.813 & 0.105 & - & - & 1.245 & 0.089 & 1.579 & 0.266 & 1.046 & 0.131 \\
\hline
\end{tabular}

Note-Missing data for N2 are the result of its death. 


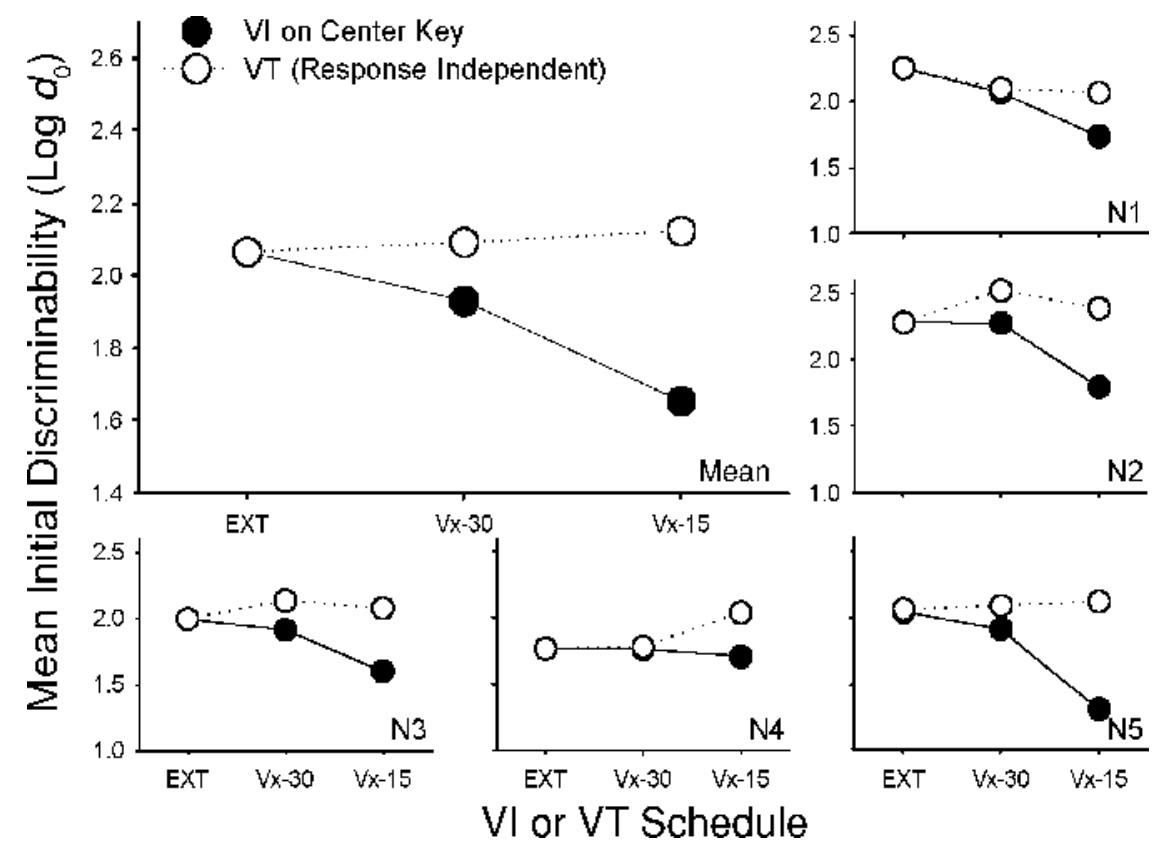

Figure 8. Mean fitted initial discriminability $\left(\log d_{0}\right)$ parameters for each center key reinforcement schedule (extinction [EXT], variable interval [VI] 30 sec, or VI 15 sec; filled circles, solid lines) and each response-independent variable-time (VT) schedule (EXT, VT 30 sec, or VT 15 sec; open circles, dotted lines) in Experiment 2. Values are shown for individuals (peripheral graphs) and averaged over pigeons (main graph). Values are averaged over reinforcer probabilities (.5 and .9), except that Pigeon $\mathrm{N} 2$ contributed data only from conditions with a reinforcer probability of .5, because it died before completing VI 30-sec and VI 15-sec conditions in which the reinforcer probability was .9. Note that EXT conditions for VI and VT are the same, using the same data.

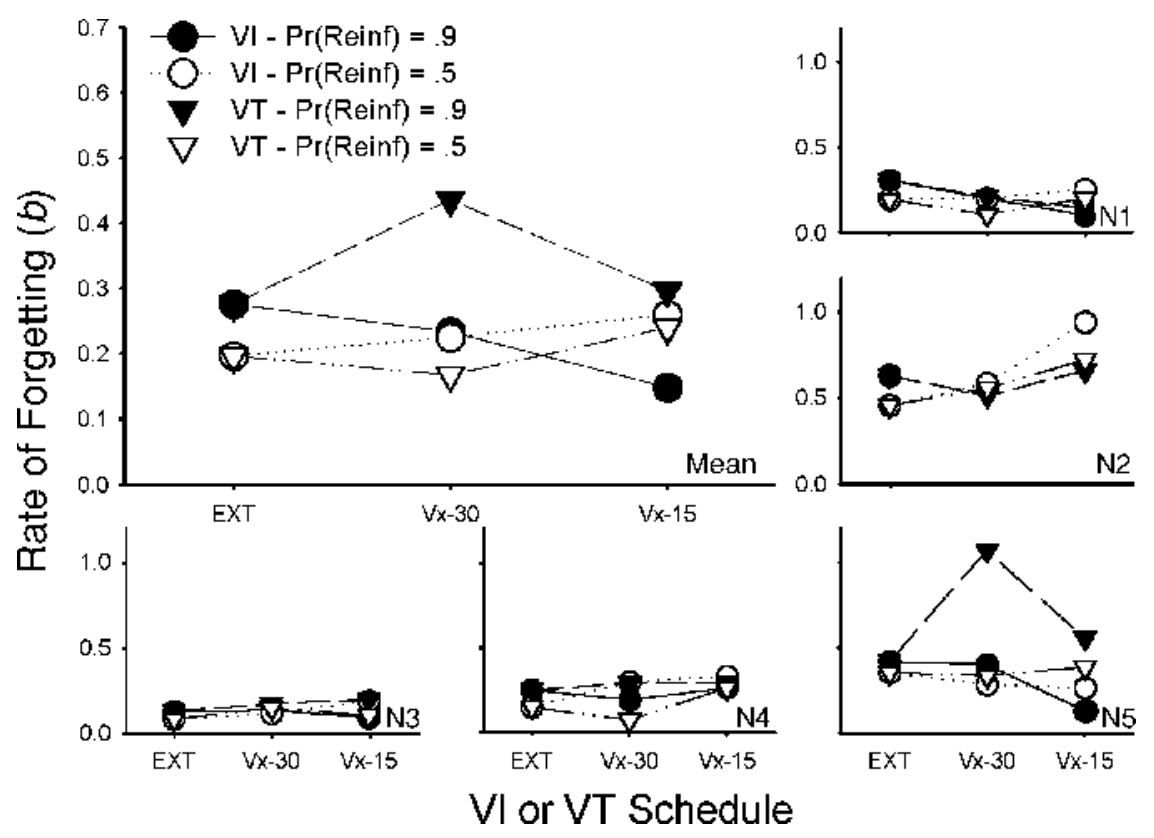

Figure 9. Mean rate of forgetting $(b)$ parameters for each center key reinforcement schedule (extinction [EXT], variable interval [VI] $30 \mathrm{sec}$, or VI $15 \mathrm{sec}$ ) and each response-independent variable-time (VT) schedule (EXT, VT $30 \mathrm{sec,} \mathrm{or} \mathrm{VT} 15 \mathrm{sec}$ ) for each reinforcer probability (.5 or .9) in Experiment 2. Values are shown for individuals (peripheral graphs) and averaged over pigeons (main graph). Pigeon $\mathbf{N} 2$ did not contribute to the displayed means, because it died before completing VI 30-sec and VI 15-sec conditions in which the reinforcer probability was .9. Note that EXT conditions for VI and VT are the same, using the same data. 

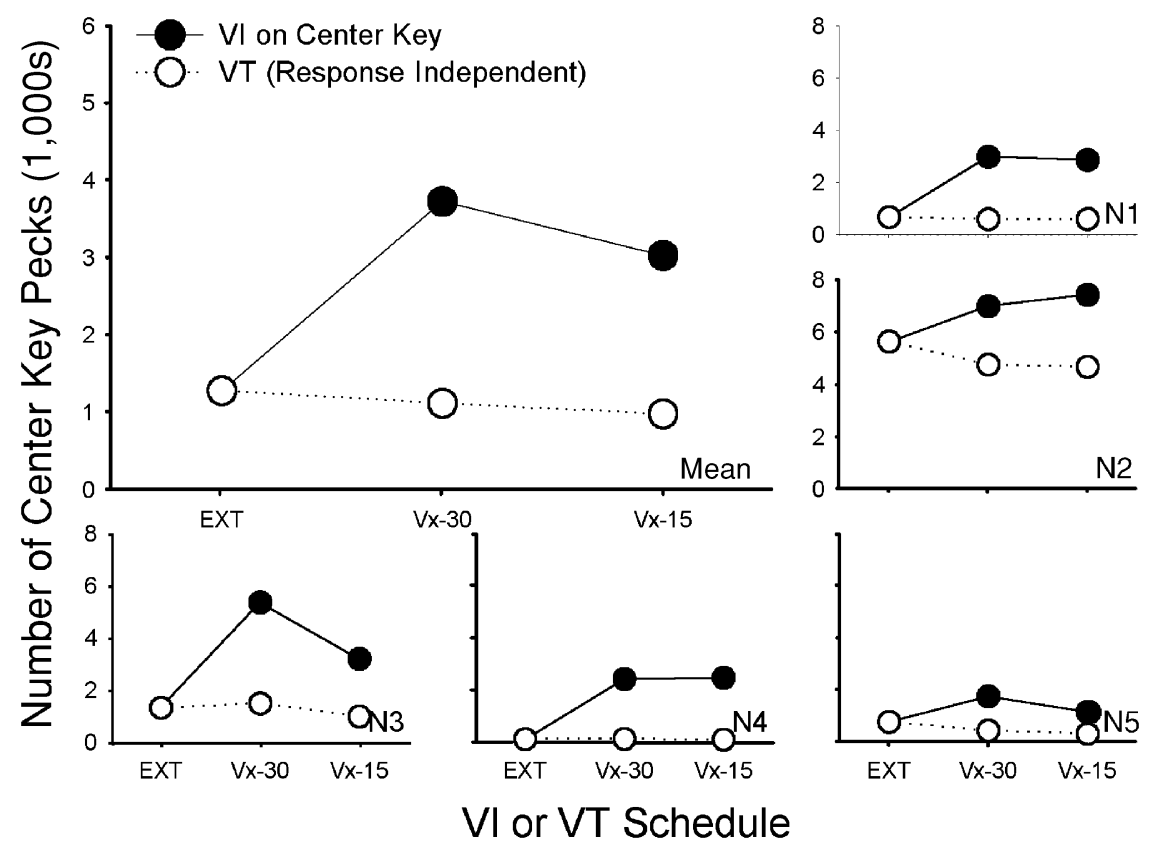

Figure 10. Mean number of center key pecks for each center key reinforcement schedule (extinction [EXT], variable interval [VI] $30 \mathrm{sec}$, or VI $15 \mathrm{sec}$; filled circles, solid lines) and each response-independent variable-time [VT] schedule (EXT, VT 30 sec, or VT 15 sec; open circles, dotted lines) in Experiment 2. Values are shown for individuals (peripheral graphs) and averaged over pigeons (main graph). Values are averaged over reinforcer probabilities (.5 and .9), except that Pigeon N2 contributed data only from conditions with a reinforcer probability of .5, because it died before completing VI 30-sec and VI 15-sec conditions in which the reinforcer probability was .9. Note that EXT conditions for VI and VT are the same, using the same data.

reinforcement for center key pecking, but also the number of center key pecks was determined by the probability of reinforcement for correct matching. That is, each behavior depended not only on its own reinforcers, but also on the reinforcers obtained by other behaviors, as in a concurrent choice procedure.

The present findings are consistent with Nevin et al.'s (2003) claim that accuracy in DMTS may possess properties similar to those of the rate of simple operant behaviors. If this assertion is true, discriminability should decrease when more reinforcement is provided for behaviors other than matching-to-sample - that is, when $R_{\mathrm{o}}$ is increased. Indeed, in the present Experiments 1 and 2, discriminability was inversely related to the rate of center key reinforcement in VI schedules, but not with VT schedules. The findings are also consistent with the related proposal that, in the presence of nonzero $R_{\mathrm{o}}$, increasing the overall probability of reinforcement for correct matching should increase initial discriminability. At first glance, part of this prediction might appear to be disconfirmed, because the effect of reinforcer probability still emerged even when no reinforcers were arranged for center key pecking. In evaluating this claim, it is important to consider that even when center key pecking was not explicitly reinforced, $R_{\mathrm{o}}$ was still present (McLean \& White, 1983; Williams, 1988). Among other possibilities, the center key was still illuminated in EXT, not only providing the opportunity to peck (which the pigeons did), but also providing a source of light that could occasion other behaviors. Therefore, the effect of reinforcer probability during center key EXT is consistent with its effects on the rates of simple operant behaviors.

Introduction of VI reinforcement of center key responses in the retention interval and variation of the probability of reinforcement for correct matching-to-sample in the present experiments were designed to test the notion that the accuracy of remembering is influenced by reinforcement for extraneous behaviors other than remembering. An obvious alternative account of the present results can be offered in terms of retroactive interference, given that the VI and VT schedules were restricted to the retention interval. For example, in the VI conditions, the reinforcement of attention and directed behaviors to another stimulus in the retention interval might compete with memory for the sample, whereas in the VT conditions, the response-independent reinforcers do not require attention to a competing stimulus. In many previous experiments, retroactive interference has been demonstrated by illuminating the normally dark retention interval (D'Amato \& O'Neill, 1971; Harper \& White, 1997; Roberts \& Grant, 1978; Salmon \& D'Amato, 1981; White, 1985). The reduction in discriminability that resulted from increasing 
the rate of center key reinforcement cannot be explained in terms of either houselight illumination or reinforcer presentation, however, because an increase in the rate of reinforcer presentation had no effect in the VT conditions in Experiment 2 (where both houselight illumination and reinforcer presentation rate were the same as those in the VI conditions). The notion that response-contingent reinforcement in the VI conditions generated attention to or stimulus control by a competing stimulus is plausible but is the same as the account in terms of extraneous reinforcement. That is, in a concurrent choice, the response alternatives are controlled by the discriminative stimuli that signal the alternative reinforcer sources. Here, we suggest that this general situation (Herrnstein, 1970) also applies to DMTS and that, together, the events of a DMTS trial constitute a discriminated operant that may compete with extraneous behaviors.

An account in terms of retroactive interference, however, is also contradicted by the result that center key reinforcement affected initial discriminability and not rate of forgetting. In previous studies of retroactive interference, rate of forgetting has increased substantially, whereas initial discriminability has been unaffected (Jans \& Catania, 1980; White, 1985). When retroactive interference is introduced in a retention interval, the increasing duration of the interfering event with progressive lengthening of the retention interval results in progressive deterioration in discriminability (Harper \& White, 1997). That is, the rate of forgetting increases. A retroactive interference account of the present results predicts greater rate of forgetting in the VI conditions than in the VT conditions in Experiment 2, because the competing stimulus (or responding on the VI schedule) is extended in duration as the retention interval progresses. This was not the present result, however. In Experiment 2, the VI and VT conditions differed in initial discriminability, and not in rate of forgetting.

In retroactive interference studies, houselight illumination during the retention interval is likely to make more $R_{\mathrm{o}}$ available. This interpretation is consistent with Wilkie, Summers, and Spetch's (1981) finding that a houselight or a geometric form on the center key, but not a tone or vibration, impairs performance both in DMTS (which requires "memory") and in a simple keypecking task (which does not). Wilkie et al.'s finding is more consistent with the view that the houselight and lit center key made more $R_{\mathrm{O}}$ available, thus affecting delayed matching and simple keypecking in a similar way. The tone and vibration are less likely to have made more $R_{\mathrm{o}}$ available and, thus, had no effect on either task. The effects of manipulating center key reinforcement rate in the retention interval in the present experiments suggest that retroactive interference effects are attributable to extraneous reinforcement and that, more generally, extraneously reinforced behaviors naturally compete with remembering.

In the present experiments, the effect of the probability of reinforcers for accurate matching, relative to the effects of reinforcers for other behaviors, was similar to the relative effects of reinforcers obtained by a simple operant (Nevin et al., 2003). This result suggests that ac- curacy or discriminability is an appropriate measure of the strength of remembering, just as response rate measures the strength of a simple operant. Every behavior has a strength that is commonly measured in such terms as rate (Herrnstein, 1961, 1970; Staddon, 1983), latency, or probability (Killeen \& Hall, 2001; Killeen, Hall, Reilly, $\&$ Kettle, 2002). In the case of the discriminated operant (remembering), the appropriate measure of strength is the measure used to show whether remembering is more or less likely - that is, accuracy or discriminability.

\section{Conclusion}

We conclude that the strength of remembering decreases when reinforcers are introduced for other behaviors. This is manifest as a reduction in initial discriminability, without an effect on the rate of forgetting. Such an outcome is consistent with models of behavior that assume that the strength of both simple and complex behaviors is determined by the reinforcers they produce, relative to the broader context of concurrent reinforcement, including extraneous reinforcement.

\section{REFERENCES}

Bizo, L. A., \& White, K. G. (1995). Reinforcement context and pacemaker rate in the behavioral theory of timing. Animal Learning \& Behavior, 23, 376-382.

Blough, D. S. (1959). Delayed matching in the pigeon. Journal of the Experimental Analysis of Behavior, 2, 151-160.

Brodigan, D. L., \& Peterson, G. B. (1976). Two-choice conditional discrimination performance of pigeons as a function of reward expectancy, prechoice delay, and domesticity. Animal Learning \& Behavior, 4, 121-124.

Brown, G. S. (2003). Memory and reinforcement. Unpublished doctoral thesis, University of Otago, Dunedin, New Zealand.

Brown, G. S., \& White, K. G. (2005). On the effects of signaling reinforcer probability and magnitude in delayed matching to sample. Journal of the Experimental Analysis of Behavior, 83, 119-128.

Brown, G. S., \& White, K. G. (in press). The optimal correction for estimating extreme discriminability. Behavior Research Methods.

D’Amato, M. R., \& O'NeILl, W. (1971). Effect of delay-interval illumination on matching behavior in the capuchin monkey. Journal of the Experimental Analysis of Behavior, 15, 327-333.

Davison, M. C., \& Tustin, R. D. (1978). The relation between the generalized matching law and signal-detection theory. Journal of the Experimental Analysis of Behavior, 51, 291-315.

DE Villiers, P. A., \& Herrnstein, R. J. (1976). Toward a law of response strength. Psychological Bulletin, 83, 1131-1153.

Fleshler, M., \& HofFMAN, H. S. (1962). A progression for generating variable-interval reinforcement schedules. Journal of the Experimental Analysis of Behavior, 5, 529-530.

Grant, D. S. (1975). Proactive interference in pigeon short-term memory. Journal of Experimental Psychology: Animal Behavior Processes, 104, 207-220.

GRANT, D. S. (1982). Samples of stimuli, responses, and reinforcers: Effect of incongruent sample type, serial position, and mode of presentation. Animal Learning \& Behavior, 10, 7-14.

Green, D. M., \& Swets, J. A. (1966). Signal detection theory and psychophysics. New York: Wiley.

Harper, D. N., \& White, K. G. (1997). Retroactive interference and rate of forgetting in delayed matching-to-sample performance. Animal Learning \& Behavior, 25, 158-164.

HERRNSTEIN, R. J. (1961). Relative and absolute strength of response as a function of frequency of reinforcement. Journal of the Experimental Analysis of Behavior, 4, 267-272.

HERRNSTEIN, R. J. (1970). On the law of effect. Journal of the Experimental Analysis of Behavior, 13, 243-266. 
Jans, J. E., \& Catania, A. C. (1980). Short-term remembering of discriminative stimuli in pigeons. Journal of the Experimental Analysis of Behavior, 34, 177-183.

JoNES, B. M., \& White, K. G. (1994). An investigation of the differentialoutcomes effect within sessions. Journal of the Experimental Analysis of Behavior, 61, 389-406.

Jones, B. M., White, K. G., \& Alsop, B. L. (1995). On two effects of signaling the consequences for remembering. Animal Learning \& Behavior, 23, 256-272.

Killeen, P. R., \& Hall, S. S. (2001). The principal components of response strength. Journal of the Experimental Analysis of Behavior, 75, 111-134

Killeen, P. R., Hall, S. S., Reilly, M. P., \& Kettle, L. C. (2002). Molecular analyses of the principal components of response strength. Journal of the Experimental Analysis of Behavior. 78, 127-160.

LoFTUS, G. R. (1978). On interpretation of interactions. Memory \& Cognition, 6, 312-319.

Luce, R. D. (1963). Detection and recognition. In R. D. Luce, R. R. Bush, \& E. Galanter (Eds.), Handbook of mathematical psychology (Vol. 1, pp. 103-189). New York: Wiley.

Macmillan, N. A., \& Creelman, C. D. (1991). Detection theory: A user's guide. Cambridge: Cambridge University Press.

McCarthy, D. C., \& Davison, M. (1986). Delayed reinforcement and delayed choice in symbolic matching to sample: Effects on stimulus discriminability. Journal of the Experimental Analysis of Behavior, 46, 293-303.

McCarthy, D. C., \& Davison, M. (1991). The interaction between stimulus and reinforcer control on remembering. Journal of the Experimental Analysis of Behavior, 56, 51-66.

McCARTHY, D. C., \& Voss, P. (1995). Delayed matching-to-sample performance: Effects of relative reinforcer frequency and of signaled versus unsignaled reinforcer magnitudes. Journal of the Experimental Analysis of Behavior, 63, 33-51.

McLean, A. P., \& White, K. G. (1983). Temporal constraint on choice: Sensitivity and bias in multiple schedules. Journal of the Experimental Analysis of Behavior, 39, 405-426.

Miyashita, Y., NaKajima, S., \& Imada, H. (2000). Differential outcome effect in the horse. Journal of the Experimental Analysis of Behavior, 74, 245-253.

Nelson, K. R., \& Wasserman, E. A. (1978). Temporal factors influencing the pigeon's successive matching-to-sample performance: Sample duration, intertrial interval, and retention interval. Journal of the Experimental Analysis of Behavior, 30, 153-162.

Nevin, J. A., \& Grosch, J. (1990). Effects of signaled reinforcer magnitude on delayed matching-to-sample performance. Journal of Experimental Psychology: Animal Behavior Processes, 16, 298-305.

Nevin, J. A., Milo, J., Odum, A. L., \& Shahan, T. A. (2003). Accuracy of discrimination, rate of responding, and resistance to change. Journal of the Experimental Analysis of Behavior, 79, 307-321.

RoBERTS, W. A. (1972). Short-term memory in the pigeon: Effects of repetition and spacing. Journal of Experimental Psychology, 94, 74-83.

RoberTs, W. A., \& Grant, D. S. (1976). Studies of short-term memory in the pigeon using the delayed matching to sample procedure. In D. L. Medin, W. A. Roberts, \& R. T. Davis (Eds.), Processes of animal memory (pp. 79-112). Hillsdale, NJ: Erlbaum.

RoberTs, W. A., \& Grant, D. S. (1978). An analysis of light-induced retroactive inhibition in pigeon short-term memory. Journal of Experimental Psychology: Animal Behavior Processes, 4, 219-236.
Rubin, C. D., \& Wenzel, A. E. (1996). One hundred years of forgetting: A quantitative description of retention. Psychological Review, 103, 734-760

Salmon, D. P., \& D'Amato, M. R. (1981). Note on delay-interval illumination effects on retention in monkeys. Journal of the Experimental Analysis of Behavior, 36, 381-385.

Sargisson, R. J., \& White, K. G. (2003). The effect of reinforcer delays on the form of the forgetting function. Journal of the Experimental Analysis of Behavior, 80, 77-94.

Staddon, J. E. R. (1983). Adaptive behavior and learning. New York: Cambridge University Press.

Trapold, M. A. (1970). Are expectancies based upon different positive reinforcing events discriminably different? Learning \& Motivation, 1, 129-140.

Weavers, R., Foster, T. M., \& Temple, W. (1998). Reinforcer efficacy in a delayed matching-to-sample task. Journal of the Experimental Analysis of Behavior, 69, 77-85.

White, K. G. (1985). Characteristics of forgetting functions in delayed matching to sample. Journal of the Experimental Analysis of Behavior, 44, 15-34.

White, K. G. (1991). Psychophysics of direct remembering. In M. L. Commons, J. A. Nevin, \& M. C. Davison (Eds.), Signal detection: Mechanisms, models and applications (pp. 221-237). Hillsdale, NJ: Erlbaum.

White, K. G. (2001). Forgetting functions. Animal Learning \& Behavior, 29, 193-207.

White, K. G., McLean, A. P., \& Aldiss, M. F. (1986). The context for reinforcement: Modulation of the response-reinforcer relation by concurrently available extraneous reinforcement. Animal Learning \& Behavior, 14, 398-404.

White, K. G., Parkinson, A. E., Brown, G. S., \& Wixted, J. T. (2004). Local proactive interference in delayed matching to sample: The role of reinforcement. Journal of Experimental Psychology: Animal Behavior Processes, 30, 83-95.

White, K. G., Ruske, A. C., \& Colombo, M. (1996). Memory procedures, performance and processes in pigeons. Cognitive Brain Research, 3, 309-317.

White, K. G., \& WiXted, J. T. (1999). Psychophysics of remembering. Journal of the Experimental Analysis of Behavior, 71, 91-113.

WILKIE, D. M., \& SPETCH, M. L. (1978). The effect of sample and comparison ratio schedules on delayed matching to sample in the pigeon. Animal Learning \& Behavior, 6, 273-278.

Wilkie, D. M., Summers, R. J., \& Spetch, M. L. (1981). Effect of delay-interval stimuli on delayed symbolic matching to sample in the pigeon. Journal of the Experimental Analysis of Behavior, 35, 153-160.

WiLliams, B. A. (1988). Reinforcement, choice, and response strength. In R. C. Atkinson, R. J. Herrnstein, G. Lindzey, \& R. D. Luce (Eds.), Stevens' Handbook of experimental psychology (2nd ed., Vol. 2, pp. 167-244). New York: Wiley.

Wixted, J. T. (1990). Analyzing the empirical course of forgetting. Journal of Experimental Psychology: Learning, Memory, \& Cognition, 16, 927-935.

Wixted, J. T., \& EbBesen, E. B. (1991). On the form of forgetting. Psychological Science, 2, 409-415.

(Manuscript received January 20, 2004; revision accepted for publication November 11, 2004.) 